\title{
Assessment of the Tolerance Level of Three Olive Intercroppings (Tomato, Eggplant and Pepper) vis- à-vis Verticillium dahliae Klebahn, at Seed and Cutting Stage
}

\author{
Darai Soumia $^{1 *}$, Chourfi Abd Elali ${ }^{1}$, Amiri Said ${ }^{2}$ and Diouri Mohammed ${ }^{3}$ \\ ${ }^{1}$ Faculty of Sciences of Meknes, Moulay Ismail University, Morocco \\ ${ }^{2}$ Department of Plant Protection and Environment, Laboratory of Plant Pathology, National School of Agriculture of Meknes, Morocco \\ ${ }^{3}$ Department of Biology, Laboratory of Plant Biotechnology and Molecular Biology, Faculty of Sciences of Meknes, Moulay Ismail University, Morocco
}

\begin{abstract}
The olive tree (Olea europaea) is an arboreal crop that has developed coping and production capabilities in diverse soil and climatic conditions in Morocco. Therefore, it has become present in virtually the entire national territory.

The olive tree is sensitive to verticillium wilt. Several isolates of Verticillium dahliae Kleb collected from olive tree, in different regions of Morocco, were tested to determine their pathogenicity. The pathogenicity of forty eight Moroccans isolates of $V$. dahliae was tested vis-à-vis tomato, eggplant and pepper.

A continuum of pathogenicity degree was observed from more to less aggressive. Isolates from North and South had very high degrees of pathogenicity. Intercroppings tested also showed tolerance degree variation toward $V$. dahliae as follows pepper was least sensitive whereas tomato was most sensitive.
\end{abstract}

Keywords: Olea europaea; Verticillium dahlia; Intercropping; Pathogenicity; Pepper; Tomato; Eggplant

\section{Introduction}

The olive tree (Olea europaea), which is the species most cultivated around the Mediterranean Sea, offers enormous potential for Morocco. Because of his great power of adaptation, the olive tree is common in many parts of the country. The Olive National Plan aims at extending this crop to cover $10^{6}$ ha in 2015 [1].

Unfortunately, the olive tree is susceptible to many diseases of bacterial, fungal and viral origins and numerous pests. Verticillium wilt, a vascular disease caused by Veritcillium dahliae [2,3], is not only a threat to the olive tree but a lethal factor.

This soil fungus is widely distributed throughout the world, it occurs throughout the temperate and subtropical regions $[4,5]$ and shows high variability in virulence, vegetative compatibility and morphology in particular.

This pathogen was reported for the first time in Morocco in the Meknes region [6]. It was met in all agricultural regions and especially in large market garden areas (Souss Massa Valley and Atlantic coast) and in the provinces of Meknes, Fez, Khemisset, Errachidia, Beni Mellal and Berkane [7].

Verticillium dahliae was encountered on tomato in many temperate and subtropical producing countries. This polyphage is able to infect more than 160 species of cultivated plants [8], Including several other solanaceous crops such as tobacco, potato, pepper and eggplant, which is particularly sensitive.

In Morocco, these crops are grown in areas ORMVA(Office de Mise en Valeur Agricole) and DPA (Direction Provincialed'Agriculture) whose main market gardening areas are Sais (Meknes and Fez), Chaouia (Settat), the axis Rabat- Khemisset and Tetouan in the north (average of the last ten years)

In DPA areas most farmers cultivate tomato pepper and eggplant as intercropping in the olive. In this situation these three crops are subject to devastation of verticillium especially in the absence of effective treatment against this disease.

Hence the interest of our study in assessing the tolerance of these three intercroppings of olive vis-à-vis 48 Verticillium dahliae isolates collected from different Moroccan olive producing regions.

This assessment will help us classify our isolates according to their virulence on the one hand and on the other hand identify the most tolerant crop to Verticillium. These data can be used for future selection of resistant or tolerant intercropping to local pathogenic strains.

\section{Materials and Methods}

\section{Origin of isolate}

Forty-eight isolates of Verticillium dahliae isolated decayed from olive whorls and infested soils, to study their pathogenicity (Table 1). They were collected from different outbreaks of the disease in the major oil-producing regions in Morocco. Harvesting was done by aeries of surveys in the years 2010 and 2011. The isolation and study of crop characteristics on ten repetitions were performed in the laboratory of Plant Pathology of ENA (Meknes National School of Agriculture (Morocco)). Isolates were purified on PDA [9], positive isolates

*Corresponding author: Darai Soumia, Faculty of Sciences of Meknes Moulay Ismail University, Morocco, Tel: 0663230228/0664735678; E-mail: soumiadarai1985@gmail.com

Received: February 06, 2014; Accepted February 24, 2014; Published February 28, 2014

Citation: Soumia D, Elali CA, Said A, Mohammed D (2014) Assessment of the Tolerance Level of Three Olive Intercroppings (Tomato, Eggplant and Pepper) vis-à-vis Verticillium dahliae Klebahn, at Seed and Cutting Stage. J Plant Pathol Microb 5: 218. doi:10.4172/2157-7471.1000218

Copyright: @ 2014 Soumia D, et al. This is an open-access article distributed under the terms of the Creative Commons Attribution License, which permits unrestricted use, distribution, and reproduction in any medium, provided the original author and source are credited. 
Citation: Soumia D, Elali CA, Said A, Mohammed D (2014) Assessment of the Tolerance Level of Three Olive Intercroppings (Tomato, Eggplant and Pepper) vis-à-vis Verticillium dahliae Klebahn, at Seed and Cutting Stage. J Plant Pathol Microb 5: 218. doi:10.4172/2157-7471.1000218

\begin{tabular}{|c|c|c|c|c|c|}
\hline Zone & Region & Year & Zone & Region & Year \\
\hline \multirow{8}{*}{ North } & \multirow{2}{*}{ A. Aicha } & 2010 & \multirow{26}{*}{ Central } & \multirow{2}{*}{ Ait Slimane } & 2010 \\
\hline & & 2011 & & & 2011 \\
\hline & \multirow{2}{*}{ Taounate } & 2010 & & \multirow{2}{*}{ A. Chgag } & 2010 \\
\hline & & 2011 & & & 2011 \\
\hline & \multirow{2}{*}{ Tissa } & 2010 & & \multirow{2}{*}{ Boufkrane } & 2010 \\
\hline & & 2011 & & & 2011 \\
\hline & \multirow{2}{*}{ Ouazzane } & 2010 & & \multirow{2}{*}{ Chlihate } & 2010 \\
\hline & & 2011 & & & 2011 \\
\hline \multirow{6}{*}{ South } & \multirow{4}{*}{ Beni Mellal } & 2010 & & \multirow{2}{*}{ El Mhaya } & 2010 \\
\hline & & 2011 & & & 2011 \\
\hline & & & & \multirow{2}{*}{ El Hajeb } & 2010 \\
\hline & & & & & 2011 \\
\hline & \multirow{2}{*}{ Chichaoua } & 2010 & & \multirow{2}{*}{ Haj Kddour } & 2010 \\
\hline & & 2011 & & & 2011 \\
\hline \multirow{4}{*}{ Est } & \multirow{2}{*}{ Taza } & 2010 & & \multirow{2}{*}{ Khemisset } & 2010 \\
\hline & & 2011 & & & 2011 \\
\hline & \multirow{2}{*}{ Gercif } & 2010 & & \multirow{2}{*}{ Oued Jdida } & 2010 \\
\hline & & 2011 & & & 2011 \\
\hline \multirow{8}{*}{ Central } & \multirow{2}{*}{ Dkhissa* } & 1995 & & \multirow{2}{*}{ Sbaa Ayoune } & 2010 \\
\hline & & 2011 & & & 2011 \\
\hline & \multirow{2}{*}{ A. Maarouf } & 2010 & & \multirow{2}{*}{ Sidislimane } & 2010 \\
\hline & & 2011 & & & 2011 \\
\hline & \multirow{2}{*}{ A. Taoujdate } & 2010 & & \multirow{4}{*}{ Ouisslane } & 2010 \\
\hline & & 2011 & & & 2011 \\
\hline & \multirow{2}{*}{ Agourai } & 2010 & & & \\
\hline & & 2011 & & & \\
\hline
\end{tabular}

*This is the 153 strain isolated in 1995 Dkhissa (Meknes) Laboratory of Phytopathology at ENA Meknes.

Table 1: List of isolates of Verticilliumdahliaefrom olive trees and infested soils used for the evaluation of virulence.

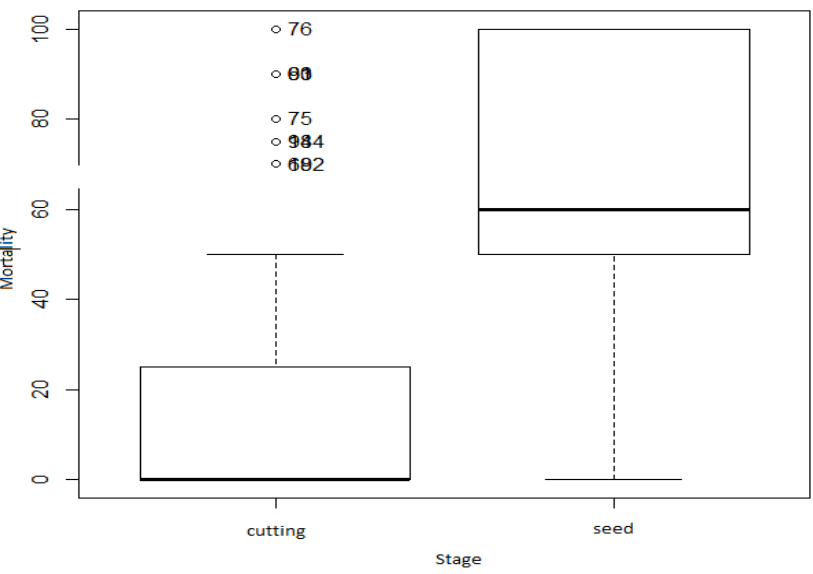

Figure 1: Distrubition mortality depending on the stage of culture.

develop a first hyaline mycelium becomes flocnneux, white and black [4] after 10 days of incubation (Figure 1). Blackening corresponds to the formation of microsclerotia (Photos 1 and 2).

Molecular characterization of all isolates was provided by conventional PCR [10] using the primer pair $\mathrm{Na} 1 / \mathrm{Na} 2$ for confirmation of Verticillium genus and the couple P19/P22 for the characterization of the $V$. dahliae species. The isolate is considered positive if it produces a band with a molecular weight 452 pd by the couple Na1/Na2 [3] (Figure 2) while the sample which sets the primer pair P19/P22 show a band $580 \mathrm{pb}$ size characteristic of the species $V$. dahliae (Photos 3 and 4) $[10]$.

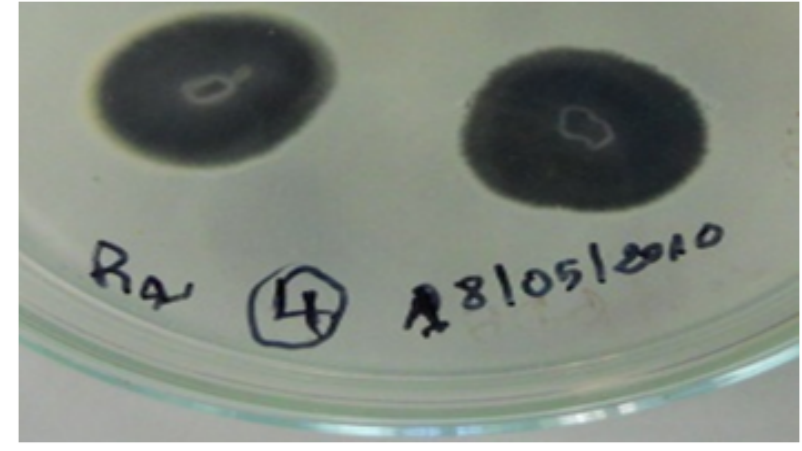

Photo 1: Colonies de Verticillium dahliae sur milieu PDA (DARAI and al. 2010.

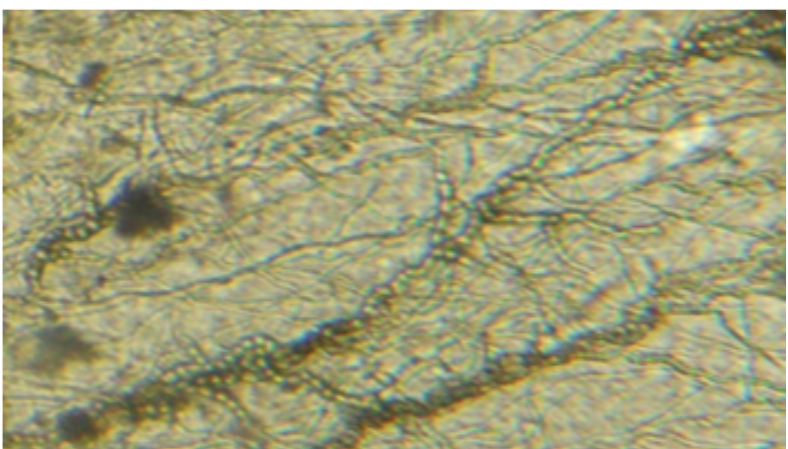

Photo 2: Microsclerotes de V. dahliae sur milieu PDA. DARAl and al. 2010.

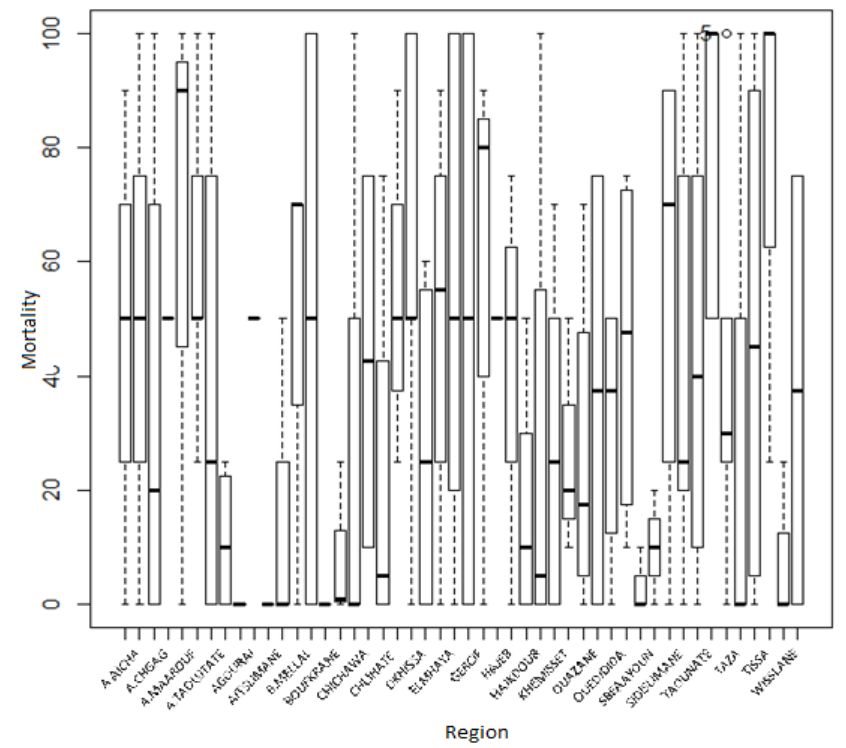

Figure 2: Variations in mortality depending on the origin of the isolate.

\section{Plant material}

The plants from tomatoes, eggplants and peppers used in our study belong to the standard varieties.

The choice of these varieties was based on their extensive use as 
Citation: Soumia D, Elali CA, Said A, Mohammed D (2014) Assessment of the Tolerance Level of Three Olive Intercroppings (Tomato, Eggplant and Pepper) vis-à-vis Verticillium dahliae Klebahn, at Seed and Cutting Stage. J Plant Pathol Microb 5: 218. doi:10.4172/2157-7471.1000218

Page 3 of 5

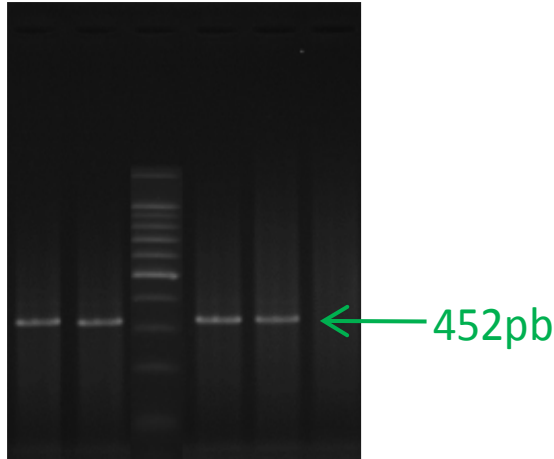

Photo 3: Profil électrophorétique des isolats 1: Taounate, 2: Beni Mellal, 3: El Mhaya et 4: Taza amplifiés par les amorces Na1 et NA2.

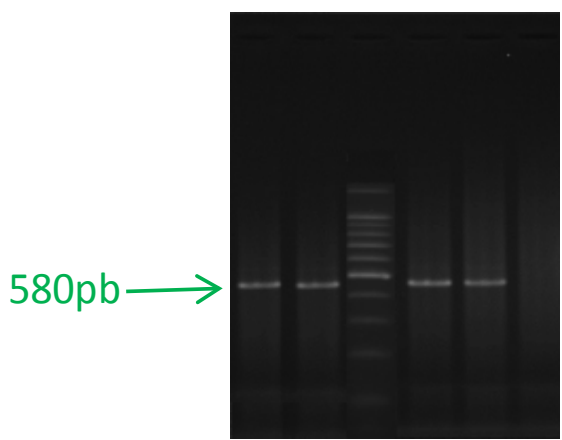

Photo 4: profil électrophorétique des isolats 1: Taounate, 2 : BeniMellal, 3 : El Mhaya et 4: Taza amplifiés par les amorces P19 et P22.

intercroppings to the olive tree, and on the feat they are the most sold in the domestic market.

\section{Inoculation of plant material by Verticillium dahliae}

Preparation of the spore solution: The colonies were scraped with a sterile blade superficially after addition of a few drops of sterile distilled water. The conidial suspensions obtained were filtered through filter paper to remove hyphal fragments.

The concentration of the suspension was adjusted using a hématocymètre. The final concentration was determined by calculating the average of 5 to 10 individual counts. Once the concentration was calculated, it is adjusted with dilutions to obtain the final working concentration $\left(10^{6}\right)$ using the following formula [11]:

\section{Concentration $($ conidia $/ \mathrm{ml})=$ Number of conidia $\times 1000 \times 50$}

Experimental monitoring protocol: The seeds were placed in jars containing $50 \%$ sterile peat and $50 \%$ sterile soil. For each plant species there were 136 pots containing 10 seeds each. For each isolate two pots were watered with $50 \mathrm{ml}$ of sterile distilled water whereas the other two were watered with $50 \mathrm{ml}$ of the spore suspension. Four other pots of each plant species were considered as control. The temperature was 24 $\pm 1^{\circ} \mathrm{C}$ under natural night.

Starting from the third week after sowing readings were made every week. After six weeks we inoculated two previously untreated pots containing cuttings of the studied crops by the same isolates.

All the results were collected on the same date two weeks after the second inoculation.

\section{Monitored parameters during the trial}

External symptoms of the disease were evaluated by the severity index, made according to the scale of Thanassoulopouloset al. [12] adapted to the treated crops. 0: healthy plant, 1: low defoliation of plants, 2 death of less than $50 \%$ of plants, 3: $60 \%$ of dead plants, 4 : $100 \%$ death of plants.

Internal symptoms of verticillium wilt were assessed according to the scale of Subbarao et al. [13] by two indices:

Root Browning Index (RBI): 1: normal appearance, 2 browning of less than $10 \%$ of roots, 3 browning about $50 \%$ of roots, 4 intensive browning and short root system [13].

-Stem Browning Index (SBI): 1: no browning, 2: browning of 25\%, 3: about $50 \%$ brown, 4 : Browning of over $50 \%$ [13].

\section{Reisolation of $V$. dahliae}

Re-isolation was made from inoculated plants. To do so, fragments of the stem, leaves and roots were recovered and then disinfected in a sodium hypochlorite solution (1/3) for $5 \mathrm{~min}$ and then rinsed three times with sterile distilled water. The fragments were planted on PDA medium with streptomycin $(25 \mathrm{mg} / \mathrm{ml})$ and chloramphenicol $(25 \mathrm{mg} /$ $\mathrm{ml})$. The culture plats were incubated for $10-15$ days at $22^{\circ} \mathrm{C}$.

\section{Statistical analysis}

Data were analysed using ANOVA and multiple linear regression procedures of the R software [14].

\section{Results}

\section{External symptoms}

The factors considered in this study were highly correlated and significantly influenced the mortality rate (Table 2 ).

The interaction region ${ }^{\star}$ stage was significant $(p=3.884108)$. The three species reacted differently to the fungus in the tow the inoculation stage. Seedlings of eggplant, tomatoes and peppers inoculated by $V$. dahliae at the seeds stage were severely affected by this pathogen. Plants inoculated at cutting stage have shown tolerance vis-à-vis $V$. dahliae (Figure 1).

Figure 1 shows that $50 \%$ of the inoculated plants were at the stage cutting a zero mortality, $25 \%$ showed a level of between 0 and $24 \%$, the rest have a rate of between 24 and 50\%. While at seedling stage, $75 \%$ of the plants have a mortality rate of between 50 and $100 \%$. Only $25 \%$ have a lower $50 \%$ rate.

Compared to control plants, the three crops responded to inoculation with the agent. This response is significantly different among crops $\left(\mathrm{p}<2.210^{-16}\right)$.

Tomato, eggplant and pepper had a high, average and low mortality

\begin{tabular}{|l|l|}
\hline Response: mortalité & $\operatorname{Pr}(>\mathrm{F})$ \\
\hline culture & $<2.2 \mathrm{e}-16^{* * *}$ \\
\hline région & $1.935 \mathrm{e}-09^{* * *}$ \\
\hline stade & $<2.2 \mathrm{e}-16^{* * *}$ \\
\hline Culture ${ }^{\star}$ région & $2.293 \mathrm{e}-08^{* * *}$ \\
\hline Culture*stade & $2.890 \mathrm{e}-06^{* * *}$ \\
\hline Région*stade & $3.884 \mathrm{e}-08^{* * *}$ \\
\hline Culture*région*stade & $0.0004671^{* * *}$ \\
\hline
\end{tabular}

Table 2: Testing the effect of three factors (culture, stage and region)on mortality. 
Citation: Soumia D, Elali CA, Said A, Mohammed D (2014) Assessment of the Tolerance Level of Three Olive Intercroppings (Tomato, Eggplant and Pepper) vis-à-vis Verticillium dahliae Klebahn, at Seed and Cutting Stage. J Plant Pathol Microb 5: 218. doi:10.4172/2157-7471.1000218

Page 4 of 5

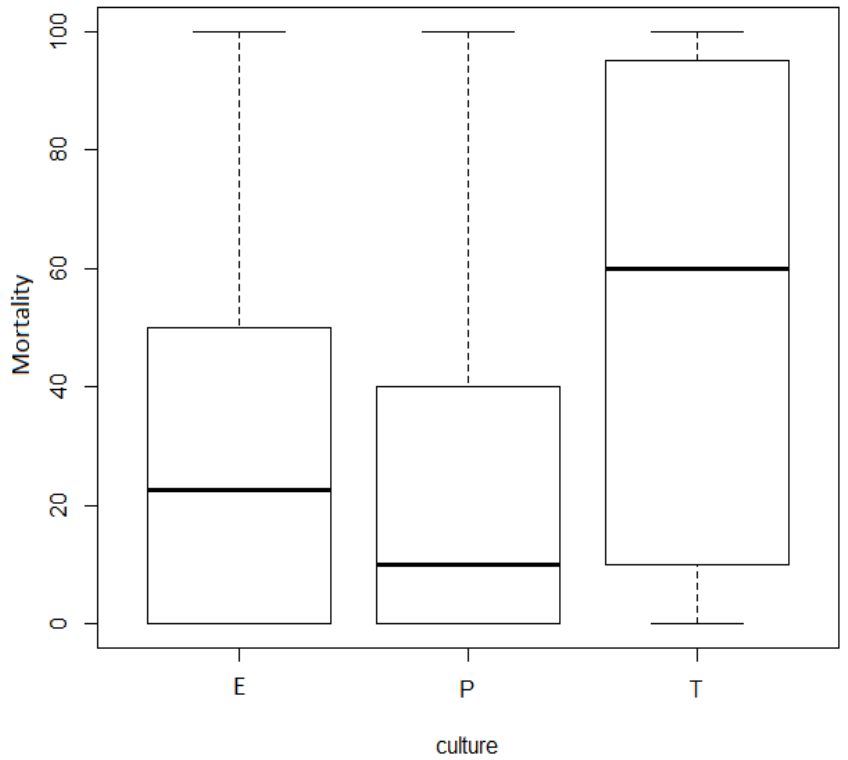

Figure 3: Distrubition mortality based on three species.

rate respectively (Figure 3).

Based on mortality, the different regions had different pathogenicity city degrees $\left(\mathrm{p}<2.29310^{-8}\right)$.

Isolates collected from Taounate region showed the highest mortality rate, followed by isolate from Beni Mellal. Isolates of the central region were characterized by a high average virulence.

Olive-growing regions of the North East are characterized by moderately severe isolates.

The lowest mortality was recorded for isolates of olive-growing regions of center facing a recent incidence of Verticilliumwilt (Ouisslane, Agourai) (Figure 2).

In parallel to the study of mortality severity indices were assigned to each studied factor combination. This index was significantly affected by the three factors considered( $\mathrm{p}<0.0001196)$. The linear regression between the variables monitored during our study showed that index significant differences were explained by mortality $\left(\mathrm{p}<2.10^{-16}, \mathrm{R}\right.$ squared: 0.8615 ).

In our study tracking numbers of fallen leaves was impossible given the virulence of isolates vis-à-vis the treated plants, resulting in the death of most infested plans before the fall of leaves. For control plants no defoliation was recorded.

\section{Plants internal response vis-à-vis isolates of Verticillium dahliae}

At the stem, browning was not regularly observed in all plants of the same batch. For the same isolate, some plants showed a clear browning while in other browning was virtually absent.

This index was highly influenced by the three factors taken into consideration $(\mathrm{p}=0.0001717)$ (Table 3$)$.

In fact browning indexes of the three cultures vis-à-vis the various isolates of $V$. dahlia had a very highly significant difference. And isolates of the pathogen affected different cribro vascular vessels of

\begin{tabular}{|l|l|}
\hline Response: mortalité & $\operatorname{Pr}(>\mathrm{F})$ \\
\hline culture & $<2.2 \mathrm{e}-16^{\star * *}$ \\
\hline région & $2.711 \mathrm{e}-08^{\star * *}$ \\
\hline stade & $<2.2 \mathrm{e}-16^{\star * *}$ \\
\hline Culture*région & $4.380 \mathrm{e}-06^{\star * *}$ \\
\hline Culture*stade & $0.0003211^{\star * *}$ \\
\hline Région*stade & $1.375 \mathrm{e}-05^{\star * *}$ \\
\hline Culture*région*stade & $0.0001717^{\star * *}$ \\
\hline
\end{tabular}

Table 3: Test the effect of three factors (culture, stage and region) on the Index Browning at the Root (RBI).

\begin{tabular}{|l|l|}
\hline Response: X.Isolement & $\operatorname{Pr}(>\mathrm{F})$ \\
\hline & $\operatorname{Pr}(>\mathrm{F})$ \\
\hline Isolat & 1 \\
\hline P.Plants & $<2 \mathrm{e}-16^{\star * *}$ \\
\hline Isolat ${ }^{*}$ P.Plants & 1 \\
\hline
\end{tabular}

Table 4: The percentage of re-isolation of the pathogen as a function of two factors, isolate andthe part of the plant for the three species tested.

the host. Isolates collected in the south zone were characterized by an average index of browning, followed by isolates from North-East and the Fez region. The highest browning index was recorded in North isolates (Taounate) and central zone.

Views culture, tomato plants showed a very high level of browning compared to eggplant while the pepper was the least affected.

The fungus slightly affected in the plants inoculated at the cutting stage. The plants off the three species inoculated at the seed stage had a relatively high browning.

The browning in the roots of these three plants varied very significantly varied depending on the plant species, the stage of inoculation and origin of isolates. The browning index in the roots followed the same trend as in the stems in the three species $\left(\mathrm{p}=2.10^{-16}\right.$, R-squared: 0.9965).

\section{The re-isolation of the pathogen}

In order to confirm and determine the distribution of the fungus in different parts of the inoculated plant, re-isolation of the pathogen was performed. The reisolation percentage was significant differences among the plants parts in all three species $\left(\mathrm{p}<2.10^{-16}\right)$. However, the percentage of positive reisolation for Forty-eight isolates showed no significant difference.This means that all isolates have a percentage high enough to allow to attribute the observed symptoms to Verticillium dahliae (Table 4)

\section{Discussion}

To estimate the pathogenicity of forty eight isolates of Verticillium dahliae collected from different olive-growing regions of Morocco, and to compare the response to $V$. dahlia of three olive intercroppings, four parameters were considered, namely the mortality rate, severity index, browning of root and aerial vascular tissues and distribution of pathogen in different parts of the plant.

Isolates of the North, the central zone and Beni Mellal showed the most severe symptoms of verticillium wilt, which is consistent with the results obtained by Cherrb et al. [8]. Based on this index tomatoes have high sensitivity with respect to all isolates.

Regarding the rate of mortality, the three species showed a tolerance to the disease when the inoculation was performed at cutting stage. 
Citation: Soumia D, Elali CA, Said A, Mohammed D (2014) Assessment of the Tolerance Level of Three Olive Intercroppings (Tomato, Eggplant and Pepper) vis-à-vis Verticillium dahliae Klebahn, at Seed and Cutting Stage. J Plant Pathol Microb 5: 218. doi:10.4172/2157-7471.1000218

Plants whose seedlings were inoculated in advance were susceptible to verticillium wilt. This significant difference between the stages of inoculation can be explained by the natural defense responses of plants [15]. In fact, the various plants mechanisms of grow in the presence of natural defense elicitors [16,17]. The presence of $V$. dahlia, an inducer of SAR (Systemic Acquired Resistance) [18], triggers and enhances resistance proteins synthesis in roots.

This idea has already been confirmed by the study of the roots of tomatoes for the revelation of the induction of SAR in the presence of Pythiumoli gandrum conducted by Picard and Tirilly [19].

The browning index of vascular tissues revealed a significant difference from one isolate to another. For some plants, this index was zero. However, the lack of browning does not mean the absence of the pathogen [8]. In fact, several isolates $V$. dahliae were positive in olive branches that had a healthy appearance.

According to Woolliams [20], the distribution of the pathogen is heterogeneous in the host tissues. The positive re-isolation of the pathogen decreases gradually as one move away from the leaves to the roots. Results similar to ours were reported by other authors about $V$. dahliae in several plants [12,21-25].

The combination of the various parameters studied showed that in general, the observed results were consistent. The degree of pathogenicity varied along a continuum from the most aggressive to the least aggressive. Isolates from North and South have very high degrees of pathogenicity.

Intercroppings tested also showed a variation in the degree of tolerance vis-à-vis $V$. dahliae. Pepper was on the top of the list while tomato showed a very high sensitivity. The presence of these vegetable crops in the original areas of pathogen influences the degree of pathogenicity of isolates on olive cultivation [8].

In light of these results, we recommend the following:

- The application of technical and cultural prophylactic.

- Avoid introduction of tomatoes, peppers and eggplant intercropped with olive.

- Perform preliminary analysis of soil before the implementation of these three cultures.

- Extend the study to other interlayers olive plants.

- Encourage varietal selection at national level of vegetable crops and olive.

\section{References}

1. Jellal $Y(2007)$ Evaluation of the level of tolerance of some olive varieties (Olea europaea L.) vis-à-vis verticillium wilt (Verticillium dahliae Klebahn) stage cutting nursery. Memory cycle engineers at the National School of Agriculture, 1.

2. Sunseri M, Johnson QA (2000) Verticillium wilt. Cooperative Extension Washington State University, Deptof Agriculture, Washington, DC

3. Rodriguez E, Garcia PA, Garcia Garrido JM, Campos M (2008) Agricultura factors affecting Verticillium wilt in olive orchards in Spain. Eur J Plant Pathol 122: 287-295.

4. Hawksworth DL, Talboys PW (1970) Descriptions of pathogenic fungi and bacteria. Phytopathology. $\mathrm{N}^{\circ} 256 \mathrm{KW}$ (England).

5. Bellahcene M, Fortas Z, Geiger JP, Mallah A,Henni D (2000) Verticllium wilt in olive in Algeria: geographical distrubition and extent of the disease. Olivae 82: 41-43.

6. Serrhini MN (1992) Important fungal diseases of olive in Morocco. Seminar on control of olive plants, Rabat.
7. ZeroualA (1994) Contribution to the study of Verticillium wilt of olive trees in Morocco. Memory cycle engineers Ecole Nationaled' Agriculture de Meknes 98.

8. Cherrab M, Zaoui D, Bennani A, Serrhini MN (1999) Variation in pathogenicity of isolates of Verticillium dahliae Kleb. After the olive in Morocco.Olivæ 84: 35-38

9. Klimes A, Stefan G, Amyotte B, Sandra Grant A, Seogchan Kang C, et al. (1976) A comparaison of soil disinfectants for effectiveness against $V$. dahliae. Gy-umlestermesztes3: 137-141.

10. OEPP/EPPO (2007-09) Vertcillium albo-atrum and Verticillum dahliae on hop Bulletin 37: 329-535.

11. Tuite (1969) Plant Pathological Methods. Fungi and bacteria. Burgess publishing company. Minneapolis MN, 239.

12. Thanassoulopoulos CC, Biris DA, Tjamos EC (1979) Survey of Verticillium wilt of olive trees in Greece. Plant Dis Rep 63: 936-940.

13. Subbarao V, Chassot A, Gordon TR, Hubbard JC, Bonello P, et al. (1995) Genetic relationships and cross pathogenicities of Verticillium dalhiae isolates from cauliflower and other crops. Phytopathology 85: 1105-1112.

14. R Core Team (2013) R: A language and environment for statistical computing. R Foundation for Statistical Computing, Vienna, Austria.

15. Kauffmann S, Dorey S, Fritig B (2001) Defense strategies. Pour la Science116-121.

16. Blanchard A, Limache F (2005) Stimulators of natural plant defenses (SND). Bibliographic report.

17. Klarzynski O etFritig B (2001) Stimilation natural plant defenses. CR Acad Sci Paris Life Sciences 324: 953-963.

18. Percival GC (2001) Introduction of systemic acquired resistance in plants: potential implication for disease management in urban forestry. Journal of Arboriculture 27: 181-192.

19. Picard K, Tirilly Y (2003) Enhancement of development and induction of resistance in tomato plants by antagonist Pythiumoligendrum. Agronomie. 23 455-460.

20. Woolliams GE (1966) Host range and symptomatology of Verticillium dahlia in economic weed, and native plants in interior british Colombia. Can J Plant Sc 46: 661-669.

21. Al-Ahmad MA, Mosli MN (1993) Verticillium wilt of olive in Syna. EPPO Bull23: 521-529.

22. Blanco-lopez MA, Jimenez-diaz RM, Caballero JM (1984) Symptomatology, incidence and distribution of Verticillium wilt in olive trees in andalucia. Phyto pathologia medeterranea 23: 1-8.

23. Chang RJ, Eastburn DM (1994) Host range of Verticillium dahlia from horse radish and pathogenicity of strains. Plant Dis 78: 503-506.

24. Estburn DM, Chang RJ (1994) Verticillium dahlia: A causal agent of root discoloration of $b$ horse radish in illinois. Plant Dis 78: 496-498.

25. Wilhelm S, Taylor JB (1965) Control of Verticillium wilt of olive through natural recovery and resistance. Phytopathology 55: 310-316. 